\title{
Real Time Monitoring of Groundwater Fluorescence: Principle and Applicability in Nepal
}

\author{
Aakriti Khadka ${ }^{1}$, Christina Oikonomou ${ }^{2}$, Shukra Raj Paudel ${ }^{1 *}$ \\ ${ }^{1}$ Department of Civil Engineering, Pulchowk Campus, Institute of Engineering \\ Tribhuvan University, Pulchowk, Lalitpur, Nepal \\ ${ }^{2}$ Frederick Research Center, Nicosia, 1303, Cyprus \\ ${ }^{\sharp}$ Corresponding author: srpaudel@ioe.edu.np
}

Received: Nov 12, 2018

Revised: $\operatorname{Dec} 25,2018$

Accepted: Jan 1, 2019

\begin{abstract}
As Nepal sits on the Indo-Eurasian plate boundary, it is highly susceptible to catastrophic earthquakes which have been posing a grave threat to the people of the country. Even though earthquake is one of the most destructive natural phenomena, its occurrence is still unpredictable. Advance warning of disastrous earthquakes is crucial so that the damage due to it is minimal. Different changes in the properties of groundwater prior to earthquake have been detected which can give important hints. Among them, the increase in fluorescent intensity of groundwater comprises a significant earthquake precursor. The positive holes, formed due to tectonic stresses in rocks with peroxy defects, interact with groundwater modifying the fluorescence intensity of water. In this study, we investigate the effect of seismic activity on the groundwater fluorescence intensity. The necessity of this examination for the country is also demonstrated. Taking into account the large variation in the groundwater quality and types of rock in Nepal, the investigation of fluorescent intensity using fluorometer may unravel different uncertainties and limitations. The simplicity of fluorometer in installation, methodology, maintenance, and its sensitivity up to large catchment area make it suitable for such investigation. Till now, variations of the groundwater fluorescent intensity have not been deeply studied in Nepal. This is of high importance in terms of earthquake forecast considering the high seismic activity in Nepal which lies on a very seismically active zone.
\end{abstract}

Key words: Water fluorescence, fluorometer, peroxy defects, fluorescent intensity

\section{Introduction}

Numerous research studies concerning different precursors of impending earthquakes have been carried out for many years. Few countries like Japan, Mexico and Taiwan have been successful to warn people about the disaster few seconds earlier [2] by detecting weaker P-waves produced by earthquake before the arrival of the slower, more destructive S-waves. However, till now, the unequivocal precursory signals that help in forecasting earthquake few days or even hours earlier are still unknown. Among various pre-earthquake phenomena, the variation in fluorescence intensity of groundwater is one of the notable earthquake precursors. The studies carried out in countries like Italy, Switzerland have reported increase in fluorescence intensity of water due to pre-earthquake activities $[3,7,10]$. 
When igneous and high graded metamorphic rocks with peroxy defects are stressed due to tectonic forces, positive holes are formed. These positive holes flow from stressed rocks to less stressed region where they react with water and organic compounds dissolved in it. This reaction results into various changes in the properties of water [8]. Due to this reaction, changes in $\mathrm{pH}$ [11], ion concentrations [21], stable isotope ratio [18], radon count rates [9], and conductivity of groundwater takes place. Apart from these changes, change in water fluorescence of water prior and post the earthquake is also detectable. Fluorescence is the emission of longer wavelength of light by a molecule that has been excited by light with a shorter wavelength and fluorescence intensity is the measurement of the emitted light [25]. In field, changes in fluorescence intensity of water are measured commonly using fluorometer. Real time monitoring of fluorescent intensity of groundwater in Nepal may be lucrative in determining correlations between changes in fluorescence and earthquakes.

The contrast in topography of Nepal gives rise to different climatic regions and there is huge variation in its natural resources. On the other hand, Nepal globally ranks $11^{\text {th }}$ position in terms of earthquake risks [22]. It sits on Indo-Eurasian plate boundary and the presence of tectonic features like Main Central Thrust (MCT), Main Boundary Thrust (MBT) and Himalayan Frontal thrust (HFT) further accelerates the seismic risk [24].The devastating 7.6 magnitude Gorkha earthquake struck Nepal on 25 April, 2015 A.D. taking away lives of approximately 9,000 people and turning more than 500,000 houses into debris [12]. Since the first recorded earthquake on 7 June, 1255 A.D. - which killed one-third of population of the Kathmandu valley - numerous major earthquakes have taken place in Nepal [12].

Even with remarkable advancement in science and technology, earthquake prediction remains a challenge. Such disastrous earthquakes leading towards terrible economical and emotional human losses need global attention. The seismic activities and easily available resources constitute Nepal a suitable place for carrying out experimental investigations about earthquakes. The main shock of Gorkha earthquake was followed by 553 aftershocks of local magnitude greater than 4.0 within the first 45 days [1] which might have provided us enough data to establish the relationship between water fluorescence and earthquake however due to the lack of proper infrastructure and planning that opportunity was missed. As earthquake shocks are still occurring in different parts of the country [13], the uncertainties about the changes in fluorescence intensity might be disclosed still in considerably short period of time. The relationships between water fluorescence and other properties of water is also a subject of study which might be of great contribution in earthquake forecasting system.

In this study, we have suggested that due to the seismicity, the variation of groundwater quality, and suitability of fluorometer, the real time monitoring of water fluorescence should be carried out shortly in Nepal. This investigation has high expectation of answering the unresolved questions about actual nature of water fluorescence intensity and earthquake.

\section{Fundamental on Groundwater Chemistry}

As igneous rocks and high graded metamorphic rocks are formed from crystallization of laden magmas, they contain solute $\mathrm{OH}^{-}$pairs. On further cooling, the $\mathrm{OH}^{-}$pair goes through redox conversion resulting into the production of peroxy defects as shown in equation (1). Two oxygen atoms, each with valence state -1 , when bonded tightly form peroxide anion which is electrically inactive [6]. 


$$
2 \mathrm{OH}^{-} \stackrel{\text { yields }}{\longrightarrow} \mathrm{O}_{2}^{2^{-}}+\mathrm{H}_{2}
$$

When such rocks are stressed due to tectonic processes, the peroxy bond gets activated. In the first step the bond gets decoupled but not dissociated. The half-broken peroxy bond receives electron from a neighboring $\mathrm{O}^{2-}$ As illustrated at Eq. (2), the electron in peroxy link gets trapped and the slectron donor oxygen atom changes to $\mathrm{O}^{-}$radical. $\mathrm{O}^{-}$in a matrix of $\mathrm{O}^{2-}$ represents a defect electron or hole $\left(h^{\bullet}\right)[6]$. The positive holes-lack of electrons- have tendency to flow into less stressed regions. At rock-water interface, as shown in Eq. (3) and (4), the positive holes charge carriers ( $O^{1^{-}}$radicals) eact with $\mathrm{H}_{2} \mathrm{O}$ forming $\bullet \mathrm{OH}$ radicals, thereby oxidizing $\mathrm{H}_{2} \mathrm{O}$ to $\mathrm{H}_{2} \mathrm{O}_{2}$ which also have capability to zause other oxidation reactions [4].

$$
\begin{aligned}
& \text { peroxy link }+\mathrm{O}^{2^{-}} \rightarrow \text { loosely bound } e^{-}+\mathrm{O}^{-}\left(\mathrm{h}^{\bullet}\right) \\
& \mathrm{O}^{-}+\mathrm{H}_{2} \rightarrow \mathrm{OH}^{-}+\bullet \mathrm{OH} \\
& \bullet \mathrm{OH}+\bullet \mathrm{OH}_{\mathrm{H}} \rightarrow \mathrm{H}_{2} \mathrm{O}_{2}
\end{aligned}
$$

The positive holes charge carriers oxidize water and organic compounds dissolved altering the fluorescent intensity of the ground water. The organic components in water responsible for the change in its fluorescence intensity are still unknown [10]. Such modifications of the fluorescence intensity can be considered as earthquake precursors [10].

\section{Discussion}

Monitoring the fluorescence intensity of groundwater due to seismic activity might be a breakthrough for earthquake prediction. Only limited number of studies has been carried out to establish the correlation between seismicity and fluorescence intensity of groundwater. Measurement of the fluorescence intensity in varieties of groundwater resources available and in different types of rocks in lower and higher Himalayas of Nepal may generate crucial hint for prediction of the disaster.

\subsection{Measurement of Fluorescence Intensity of Groundwater}

Variations in different properties of ground water prior to seismic events have been proven to be associated with the impending earthquakes[14].Changes in fluorescent intensity were observed in 1999 using synchronous scans of fluorescent spectra in water samples collected prior and post Izmit earthquake in Turkey . In water samples collected 7 weeks prior to the Izmit earthquake from different locations of Turkey showed remarkable rise in fluorescence intensity [3]. Two earthquakes with magnitudes of 6.0 and 5.8 occurred in Modena City in Northern Italy on May 20, 2012, and on May 29, 2012 respectively. Mineral water of brands Lieta, Ventasso, Cerelia and Monte Cimone bottled before and after these two shocks were collected and their fluorescence intensity was analyzed using the synchronous scanning method. It was found that the fluorescence intensity of the investigated Monte Cimone water samples reported significant increase from April 21, 2012 i.e. many days before the occurrence of the two earthquakes [7]. In 2015, fluorescence intensity using GGUN-FL30 fluorometer was monitored in two different springs of Baden and Rheinfelden, Switzerland for a period of 11 weeks. The results also documented increase in fluorescence intensity of water days before the occurrence of minor earthquake in Andelfingen [10]. The results of such different observations presented the detectable increase in fluorescence 
intensity days before impending earthquake which can be used for early warning. Further detail investigation is necessary to find the definite nature of fluorescence intensity of water.

Fig. 1 presents the arrangement of fluorometer on the field for real time monitoring of fluorescence intensity of groundwater. The optical system of the fluorometer is immersed in groundwater and the water flows through a quartz tube inside a steel case. The system consists of LEDs and light source that can be used to excite the fluorescent components in the water. The emissions of the excited fluorescent components of water are filtered to determine the wavelength range detected by photodiodes [16].The received signal is transferred to the data logger consisting of acquisition parts and batteries. The data can be directly displayed for real time monitoring or can be stored for future analysis. Since the installation, methodology and maintenance of fluorometer is convenient it may be further used in many other places for real time monitoring. The sensitivity of the device is up to wide catchment area and with wide range of wavelength of spectrum [10].

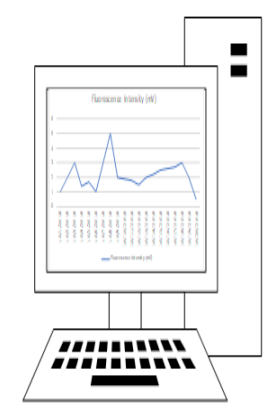

Real Time Monitoring System

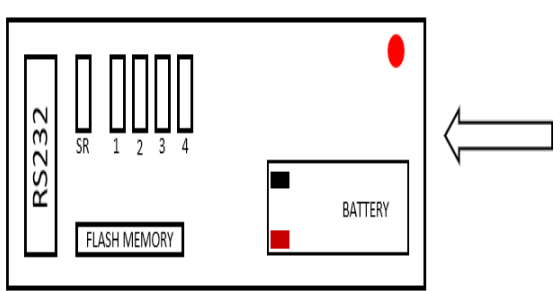

Data Logger

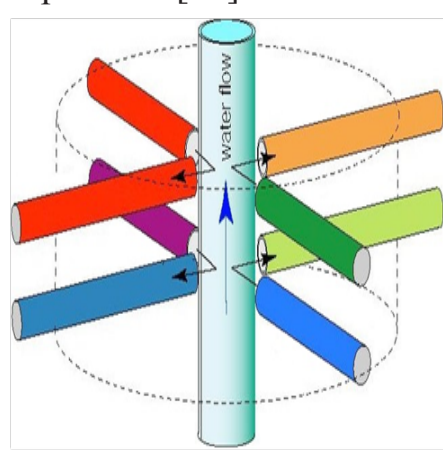

Optical System of Fluorometer

Fig. 1: Schematic diagram of fluorometer arrangement for real time monitoring of water fluorescence on the field (modified after Schnegg, 2002)

The imprecise but propitious results present the need of further investigation about behavior of groundwater during earthquake in more suitable countries. Experiments carried out so far is still insufficient to determine the expected shape and duration of increasing fluorescence intensity curve prior to earthquake, therefore a real time monitoring of water fluorescence using fluorometer in seismically active zone with abundant resources, such as Nepal, is essential.

Currently, the fluorometer application is widely used in various scientific fields. Determination of fluorescence yield was first accomplished by Vavilov in 1924 and the invention of fluorometer was initiated by antimalarial research during World War II to calculate the amount of drug reached to the blood. Application of fluorometer for real time monitoring of fluorescence intensity of groundwater could be exploited for the purpose of earthquake prediction.

\subsection{Applicability of Water Fluorescence Monitoring in Nepal}

Fluorescent intensity changes were first observed in 1999 and many studies have been carried out regarding peroxy and positive hole charge carriers which are responsible for such changes. But till date, the numbers of dissolved organic substances that are present in the oxidation reaction involving the charge carriers are unknown. In addition, the external factors which influence the fluorescence intensity besides aquifer mixing and anthropogenic influxes are not yet known[10]. Nepal is not only seismically active but it is also naturally blessed with diverse rock composition 
and immense underground water resources that can be exploited to elucidate such uncertainties. Only within area of $147181 \mathrm{~km}^{2} \mathrm{Nepal}$ has diverse environment resulting from its large topographic variation consisting of low flat lands of Terai to enormous steep peaks including world's highest mountain, Mount Everest [24]. Therefore, the installation of fluorometer in several regions with various types of groundwater resources in Nepal, it may help to divulge the different factors influencing the fluorescene, such as the igneous and metamorphic rocks which are formed by cooling produce peroxy and positive holes under seismic stress [19]. High Himalayan and lesser Himalayan zones of Nepal are covered with suitable varieties of metamorphic rocks which favor the establishment of fluorometers.

- Higher Himalayan zone is characterized by the presence of high grade metamorphic rocks; mostly gneisses of various types. The lower succession consists of Kyanite-Silliminite gneisses and some quartzites. The middle part consists of calcareous gneisses interbedded with argillites. The top most part comprises of augen gneisses, granitic gneisses and migmatites. Acid magmatism is the major part of top sequence consisting of layers of leuco-granites, granitic gneisses and pegmatites [5].

- Lesser Himalayan crystallines consist of metamorphosed rock sequence somewhere overlies by fossiliferous sedimentary cover. Typical rock types are schists, phyllites, quartzites, limestones, dolomites as well as argillo-arenaceous and argillo-calcareous rocks with horizons of marble beds. This zone is intruded by granite rocks and gnessified [5].

In real time monitoring of the water fluorescene, fluorometer is completely submergered in groundwater [16]. Thus, continuous availability of groundwater in the working field is also crucial for this investigation. There are various locations in Nepal where sources of groundwater are abundant. According to Water Environment Partnership in Asia, the groundwater sources of the country get recharged by $12 \mathrm{~km} 3$ per year. Groundwater is available in most parts of the country, however the amount and depth vary from place to place. In the Terai, the upper unconfined aquifer $(50-60 \mathrm{~m})$ has been considered as good productive shallow zones and most of groundwater production is limited to upper $250 \mathrm{~m}$ [17]. Groundwater resources recharge in the Terai is estimated to be $8800 \mathrm{MCM} /$ year [17].

Besides investigating of rock characteristics, groundwater condition and chemistry, specific river basins can be selected by analyzing seismicity - earthquakes (greater than 4 magnitudes) in each watershed which occurred within 2000 A.D. to 2018 A.D. [23]. It was observed that the frequency of occurrence was notable in Bagmati, Gandaki and Karnali Basins. So, these regions may be favorable for installation of fluorometer. Inspection of fluorescent intensity of water samples from various thermal springs located in suggested basins [15] can also be done regularly as performed in Italy [7]. This will help in verification of the result obtained from real time monitoring system. But different other factors like human disturbances to water flow, quality of water, transportation facilities, and power supply are also considered while selecting the site for the installation.

Past records show that places like Dolakha and Sindupalchowk which were the epicenters of the major earthquakes in 2015 are still seismically active [13]. Sindupalchowk and Dolakha lies in lower and upper Himalayan zones with Main Central Thrust in between them [20]. Many parts of these places have not been urbanized yet so, anthropogenic influxes which affect the components of groundwater resources need not be taken into account for real time monitoring of water fluorescence. Proper study and analysis should be further done for such places which are favourable for installing fluorometer. Minor earthquakes of magnitude 4 are still common in Nepal 
as a result of aftershocks of 2015 earthquake [13]. Also because of tectonic features of Nepal, new earthquakes are probable to occur. Taking advantage of current seismicity of the country, the real time monitoring of water fluorescence might answer countless global questions about pre-earthquake events. Examination in various ground water sites with different seismicity and extended monitoring periods will provide enough measurements. And, proper analysis can unravel the shape of fluorescence intensity curve and move us closer to the one of the biggest challenge of modern science, i.e. earthquake prediction.

\section{Conclusion}

In present situation, it is essential of real time monitoring of water fluorescence to be carried out in Nepal. The proposed technology is applicable with respect to rock composition, seismicity and groundwater condition of Nepal. The appropriate places for the installation of the fluorometer among the suggested river basins should be studied in detail so that more precise results could be obtained. The behavior of other parameters of water and fluorescence prior to earthquake should also be correlated along with other earthquake precursors. Because of the uncertainty of occurrence of earthquake, people in seismically active zone are always in fear of it. The nature of long term fluorescence curve along with other pre-seismic signatures may help predict earthquake day to a week before. Such crucial information finally may help forecast, plan and prepare to the earthquake too. Earthquake forecasting system however requires long term observation of multiple parameters such as ionospheric perturbations, groundwater fluorescence, and other pre-seismic events- if possible to be installed- will save countless lives and the properties that invites due to earthquake.

\section{References}

[1] Adhikari LB, Gautam UP, Koirala BP, Bhattarai M, Kandel T, Gupta RM, Timsina C, Maharjan N, Maharjan K, Dahal T and Hoste-Colomer R (2015), The aftershock sequence of the 2015 April 25 Gorkha-Nepal earthquake, Geophysical Supplements to the Monthly Notices of the Royal Astronomical Society, 203 (3): 2119-2124.

[2] Allen RM, Gasparini P and Kamigaichi O (2009), Earthquake early warning, Seismological Research Letters, 80: 682-782.

[3] Balderer W and Leuenberger F (2007), Observation of fluorescence spectra of groundwater in areas of tectonic activity: Could it act as a precursor of earthquakes? Geochemical Precursors of Earthquakes: Proceedings of the International Brainstorming Session on Geochemical Precursors of Earthquakes 11-13 September 2006, 22-30.

[4] Balk M, Bose M, Ertem G, Rogoff DA, Rothschilda LJ and Freund FT (2009), Oxidation of water to hydrogen peroxide at the rock-water interface due to stress-activated electric currents in rocks, Earth and Planetary Science Letters, 283(1-4): 87-92.

[5] Dhakal S (2014), Geological divisions and associated hazards in Nepal, Contemporary Environmental Issues and Methods in Nepal, Central Department of Environmental Science, Tribhuvan University Nepal, 100-109.

[6] Freund FT and Freund MM (2015), Paradox of peroxy defects and positive holes in rocks, Part I: Effect of temperature, Journal of Asian Earth Sciences, 114: 373-383.

[7] Fidani C, Balderer W and Leuenberger F (2017), The Possible Influences of the 2012 Modena Earthquakes on the Fluorescence Spectra of Bottled Mineral Water, Hydrology Current Research, 8 (288): 2 . 
[8] Grant RA, Halliday T, Balderer WP, Leuenberger F, Newcomer M, Cyr G and Freund FT (2011), Ground water chemistry changes before major earthquakes and possible effects on animals, International journal of Environmental Research and Public Health, 8 (6): 1936-1956.

[9] Igarashi G, Saeki S, Takahata N, Sumikawa K, Tasaka S, Sasaki Y, Takahashi M and Sano Y (1995), Ground-water radon anomaly before the Kobe earthquake in Japan, Science, 269 (5220): 60-61.

[10] Mäder M, Leuenberger F and Balderer W (2018), Effects of seismic activity on the fluorescence signal of groundwater, Geoenvironmental Disasters, 5(1) : 9.

[11] Malakootian M and Nouri J (2010), Chemical Variations of Ground Water Affected by the Earthquake in bam region Malakootian, M. International Journal of Environmental Research, 4(3): 443-454.

[12] National Planning Commission (2015), Nepal earthquake 2015: Post disaster needs assessment, Vol. A: Key Findings. Government of Nepal, National Planning Commission.

[13] National Seisomological Center, Nepal, Available online at http://seismonepal.gov.np/ earthquakes.

[14] Paudel SR, Banjara SP, Wagle A and Freund FT (2018), Earthquake chemical precursors in groundwater: a review, Journal of Seismology, 22 (5): 1293-1314.

[15] Ranjit M (1994), Geochemical studies of some thermal springs in Nepal, United Nations University.

[16] Schnegg PA (2002), An inexpensive field fluorometer for hydrogeological tracer tests with three tracers and turbidity measurement, In Articles of the Geomagnetism Group at the University of Neuchâtel, Groundwater and Human Development, 1484-1488.

[17] Shrestha SR, Tripathi GN and Laudari D (2018), Groundwater Resources of Nepal: An Overview. In Groundwater of South Asia, 169-193.

[18] Skelton A, Andrén M, Kristmannsdóttir H, Stockmann G, Mörth CM, Sveinbjörnsdóttir Á, Jónsson S, Sturkell E, Guðrúnardóttir HR, Hjartarson H and Siegmund H (2014), Changes in groundwater chemistry before two consecutive earthquakes in Iceland, Nature Geoscience, 7 (10): 752 .

[19] Takeuchi A, Lau BW and Freund FT (2006), Current and surface potential induced by stressactivated positive holes in igneous rocks, Physics and Chemistry of the Earth, 31(4-9): 240-247.

[20] Tater JM (1978), Geological map of Nepal.

[21] Tsunogai U and Wakita H (1995), Precursory chemical changes in ground water: Kobe earthquake, Japan, Science, 269 (5220): 61-63.

[22] United Nations Development Programme, Bureau for Crisis Prevention and Recovery (2004), Reducing Disaster Risk: A Challenge for Development-a Global Report, United Nations.

[23] United States Geological Survey (2018), Available in online: www.earthquake.usgs.gov.

[24] Upreti BN (1999), An overview of the stratigraphy and tectonics of the Nepal Himalaya, Journal of Asian Earth Sciences, 17 (5-6): 577-606.

[25] Valeur B and Berberan-Santos MN (2012), Molecular fluorescence: principles and applications, John Wiley \& Sons. 